\title{
Exigências em treonina para frangos de corte de 22 a 42 dias de idade ${ }^{1}$
}

\section{Karina Ferreira Duarte ${ }^{2}$, Otto Mack Junqueira ${ }^{2}$, Rosemeire da Silva Filardi ${ }^{3}$, Jefferson Costa de Siqueira ${ }^{4}$, Edivaldo Antônio Garcia ${ }^{5}$, Antonio Carlos de Laurentiz ${ }^{3}$}

\footnotetext{
1 Processos FAPESP 2005/55549-0 e 2005/56680-3.

2 Departamento de Zootecnia da Universidade Estadual Paulista Júlio de Mesquita Filho, Faculdade de Ciências Agrárias e Veterinárias de Jaboticabal - UNESP.

${ }^{3}$ Departamento de Biologia e Zootecnia da Universidade Estadual Paulista Júlio de Mesquita Filho, Faculdade de Engenharia de Ilha Solteira UNESP

${ }^{4}$ Centro de Ciências Agrárias e Ambientais da Universidade Federal do Maranhão - UFMA.

${ }^{5}$ Departamento de Produção Animal da Universidade Estadual Paulista Júlio de Mesquita Filho, Faculdade de Medicina Veterinária e Zootecnia de Botucatu - UNESP.
}

RESUMO - Um experimento foi realizado com o objetivo de estabelecer critérios de avaliação das exigências de treonina digestível para frangos de corte de 22 a 42 dias de idade utilizando-se diferentes modelos de regressão (quadrático, exponencial e de retas segmentadas ou Linear Response Plateau). Foram utilizados 1.920 frangos de corte machos com 22 dias de idade, distribuídos em delineamento inteiramente ao acaso, com seis tratamentos (seis níveis de treonina digestível: 0,5904; 0,6441; 0,6977; 0,7514; 0,8051 e $0,8588 \%$ ) e oito repetições de 40 aves. Utilizou-se como padrão o nível de 0,6977\% de treonina digestível. Foram avaliados dados de desempenho e características de carcaça. Com base nos dados, o nível de 0,7642\% de treonina digestível, correspondente às relação treonina:lisina digestível de 71,19\%, promoveu o melhor resultado de conversão alimentar de acordo com o modelo Linear Response Plateau.

Palavras-chave: aminoácidos digestíveis, análises de regressão, desempenho, proteína ideal, treonina digestível

\section{Threonine requirements of 22 to 42 -day-old broilers}

\begin{abstract}
The objective of this experiment was to establish different criteria for evaluation of the requirements of digestible threonine for broilers from 22 to $42 \mathrm{~d}$ of age, using different regression models (quadratic, exponential, and Linear Response Plateau). A total of 1,920 22-day-old male Cobb broilers were distributed in randomized experimental design, with six treatments (six threonine levels: $0.5904,0.6441,0.6977,0.7514,0.8051$, and $0.8588 \%$ ) and 8 replications containing 40 broilers each one. The level of $0.6977 \%$ digestible threonine was used as standard. Data on performance and carcass characteristics were evaluated. Based on the data, the threonine level of $0.7642 \%$, corresponding to the threonine:digestible lysine ratio of $71.19 \%$ had the best result for feed conversion, according to the Linear Response Plateau model.
\end{abstract}

Key Words: digestible amino acids, digestible threonine, ideal protein, performance, regression analyses

\section{Introdução}

A treonina é um hidróxi-aminoácido que desempenha papel importante junto com a glicina e a serina no metabolismo da porfirina. Tem participação essencial na síntese de proteína corporal, é essencial na manutenção da saúde e da integridade intestinal. É também um componente importante no desenvolvimento das penas, participando em 4 a $5 \%$ de seu conteúdo de proteína bruta (Kidd, 2000). Incorpora-se às proteínas e às enzimas em um índice molar de 6\% em comparação aos outros aminoácidos (Henty \& Séve, 1993).

Em dietas basais, é tipicamente o terceiro aminoácido limitante para frangos de corte, após metionina + cistina e lisina e seu nível nutricional mínimo pode estabelecer o

Recebido em 5/7/2010 e aprovado em 6/7/2011.

Correspondências devem ser enviadas para: karinafduarte@yahoo.com.br nível de proteína bruta da dieta se não for utilizada a forma sintética (Berres et al., 2007). Deficiência em treonina em rações para frangos de corte pode diminuir a eficiência de utilização da metionina + cistina e da lisina (Atencio et al., 2004). Formular dietas de custo mínimo para frangos de corte e que atendam às exigências em treonina é essencial para expressão do máximo potencial genético das aves e para redução do desequilíbrio entre os aminoácidos.

A exigência de treonina para frangos de corte no período de 22 a 42 dias de idade, segundo as recomendações do NRC (1994), é de 0,74\% em rações com 3.200 kcal EM/kg de ração. Rostagno et al. (2000) e Rostagno et al. (2005) recomendaram valores de treonina digestível de 0,61 e de $0,69 \%$, respectivamente, para frangos de 22 a 42 dias de idade. 
Segundo Fernandez et al. (1994), a exigência de treonina para mantença é alta em relação à dos demais aminoácidos, em função de seu grande conteúdo nas secreções intestinais endógenas. Assim, a treonina apresenta maior importância em fases avançadas de desenvolvimento, pois as proporções de exigências para mantença são altas nessa fase.

Kidd \& Kerr (1996), em extensa revisão bibliográfica, concluíram que existem controvérsias em relação às atuais exigências de treonina para frangos de corte, pois ainda não se estabeleceu a maneira apropriada para expressar essas exigências em relação à porcentagem da dieta, energia metabolizável, proteína bruta ou em relação à lisina. Diante do exposto, objetivou-se com este estudo avaliar as exigências em treonina digestível de frangos de corte na fase de 22 a 42 dias de idade.

\section{Material e Métodos}

O experimento foi realizado no Aviário Experimental do Departamento de Zootecnia da Faculdade de Ciências Agrárias e Veterinárias do Campus de Jaboticabal - UNESP durante 22 a 42 dias de idade das aves. Foram utilizados 1.920 pintos machos de 1 dia de idade, da linhagem Cobb, alojados em galpão de alvenaria com 80 boxes.

O aquecimento inicial foi realizado por meio de lâmpadas de infravermelho de 250 watts, procurando manter a temperatura ambiente entre 28 e $30{ }^{\circ} \mathrm{C}$ durante as duas primeiras semanas de vida. Os pintos foram vacinados contra as doenças de marek, gumboro e bouba no incubatório, seguindo-se a vacinação no 5 으 e 21 으 dias contra a doença de gumboro e no $8^{\circ}$ dia contra a doença de New Castle.

A cama utilizada foi de maravalha e a quantidade colocada em cada boxe foi de 1,2 kg de matéria seca/ave alojada, de modo que todos os tratamentos tiveram a mesma quantidade inicial deste material utilizado como cama a uma altura de $5 \mathrm{~cm}$. O programa de luz adotado foi de 24 horas de luz durante todo o período experimental. Durante todo o período experimental, as aves receberam ração e água à vontade.

Durante o período inicial ( 1 a 21 dias de idade), as aves foram criadas em galpão experimental recebendo ração com $3.005 \mathrm{kcal}$ de EM/kg e 21,6\% de PB, para satisfazer suas exigências nutricionais, segundo as médias das recomendações de Rostagno et al. (2005) para as fases de 1 a 7 e 8 a 21 dias de idade. Ao final do $21^{\underline{0}}$ dia de idade, os frangos foram pesados, selecionados seguindo-se o critério do peso médio de cada boxe e distribuídos em delineamento experimental inteiramente casualizado, envolvendo seis tratamentos (níveis de treonina digestível), cada um com oito repetições de 40 aves.

$\mathrm{Na}$ formulação das rações experimentais, foram consideradas as recomendações nutricionais de proteína bruta, energia metabolizável, cálcio, fósforo disponível e aminoácidos digestíveis estabelecidas por Rostagno et al. (2005) para as fases de 22 a 33 e 34 a 42 dias de idade.

Foram realizadas as análises químico-bromatológicas dos ingredientes das rações experimentais (Tabela 1), de acordo com os métodos descritos por Silva (1990). Os valores de energia metabolizável (EM) e dos coeficientes de digestibilidade utilizados foram os estabelecidos por Rostagno et al. (2005).

Os tratamentos consistiram do fornecimento de uma dieta basal deficiente em treonina, formulada com base em aminoácidos digestíveis, de acordo com o conceito de proteína ideal, durante 22 a 42 dias de idade, suplementadas com cinco níveis de treonina digestível.

A ração basal (Tabela 2) foi formulada para conter 0,5904\% de treonina digestível, que corresponde a 55\% do nível 1,0735 de lisina, e as outras rações com níveis crescentes de $5 \%$ em relação à ração basal, as quais contiveram 0,$6441 ; 0,6977 ; 0,7514 ; 0,8051$ e 0,8588 , ou seja, dois níveis abaixo e três acima do nível de 0,6977\% recomendado por Rostagno et al. (2005). Os níveis de lisina, metionina + cistina e dos demais aminoácidos utilizados na formulação das rações foram os estabelecidos por Rostagno et al. (2005).

A adição de treonina à dieta basal foi feita em substituição ao ácido glutâmico, no intuito de manter todos os tratamentos com o mesmo nível de nitrogênio e eliminar qualquer efeito relacionado a diferenças em sua concentração. Portanto, as dietas com menores níveis de treonina continham maiores níveis de ácido glutâmico.

As aves foram pesadas no início e ao final do período experimental para determinação do ganho de peso, pela diferença entre as pesagens entre o $21^{\underline{0}}$ e $42 \underline{0}$ dias. Da mesma forma, o consumo de ração foi obtido pela diferença entre a ração fornecida e as sobras das rações nos comedouros. Posteriormente, foi calculada a conversão alimentar pela razão entre o consumo de ração e o ganho de peso das aves. A viabilidade criatória foi obtida tomando-se o número total de aves alojadas menos as aves mortas ou retiradas da parcela, dividido pelo total de aves alojadas (multiplicado por 100). Para cálculo do índice de eficiência produtiva (IEP = [ganho de peso médio diário $(\mathrm{g}) \times \mathrm{VC}(\%)] /$ (conversão alimentar $\times 10$ ), consideraram-se o ganho de peso, o consumo e a conversão alimentar média das aves nessa idade. 
Tabela 1 - Composição químico-bromatológica e de aminoácidos totais e digestíveis dos ingredientes das rações experimentais

\begin{tabular}{lcc}
\hline & & Composição químico-bromatológica \\
\cline { 2 - 3 } & Milho & Farelo de soja \\
\hline Matéria seca, \% & 88,90 & 89,10 \\
Proteína bruta, \% & 8,11 & 44,40 \\
Energia metabolizável, kcal/kg & 3381 & 2256 \\
Extrato etéreo, \% & 3,61 & 1,66 \\
Fibra bruta, \% & 1,73 & 5,41 \\
Cálcio, \% & 0,03 & 0,24 \\
Fósforo disponível, \% & 0,08 & 0,18 \\
Sódio, \% & 0,02 & 0,02 \\
\hline
\end{tabular}

Sódio, \%

Composição em aminoácidos

\begin{tabular}{|c|c|c|c|c|}
\hline & Aminoácidos totais & Aminoácidos digestíveis & Aminoácidos totais & Aminoácidos digestíveis \\
\hline Alanina & 0,59 & 0,55 & 1,94 & 1,90 \\
\hline Arginina & 0,36 & 0,33 & 3,19 & 3,06 \\
\hline Glicina & 0,31 & 0,30 & 1,89 & 1,88 \\
\hline Isoleucina & 0,27 & 0,24 & 2,01 & 1,83 \\
\hline Leucina & 0,97 & 0,92 & 3,42 & 3,12 \\
\hline Lisina & 0,23 & 0,20 & 2,72 & 2,50 \\
\hline Cistina & 0,18 & 0,16 & 0,62 & 0,60 \\
\hline Metionina & 0,17 & 0,16 & 0,60 & 0,54 \\
\hline Metionina + cistina & 0,35 & 0,32 & 1,22 & 1,06 \\
\hline Fenilalanina & 0,39 & 0,35 & 2,32 & 2,15 \\
\hline Tirosina & 0,24 & 0,21 & 1,50 & 1,47 \\
\hline Treonina & 0,29 & 0,24 & 1,74 & 1,53 \\
\hline Triptofano & 0,06 & 0,05 & 0,58 & 0,52 \\
\hline Valina & 0,39 & 0,34 & 2,13 & 1,90 \\
\hline Histidina & 0,24 & 0,22 & 1,16 & 1,10 \\
\hline Serina & 0,39 & 0,34 & 2,29 & 2,24 \\
\hline
\end{tabular}

${ }_{1}^{1}$ Aminoácidos totais, determinados pelo Laboratório da Degussa - Animal Nutrition Service - São Paulo, SP.

2 Aminoácidos digestíveis, calculados com base nos coeficientes de digestibilidade descritos nas Tabelas Brasileiras para Aves e Suínos (2005).

Ao final do período experimental, foram selecionadas oito aves por parcela com peso corporal próximo ao peso médio da respectiva parcela. As aves selecionadas foram submetidas a um período de jejum de 6 horas, sacrificadas por sangria da jugular, depenadas, evisceradas e, após pesagem da carcaça, foram divididas em cortes para avaliação dos rendimentos de carcaça (desconsiderando cabeça, pescoço e pés), peito, coxa + sobrecoxa, asas e dorso.

As análises estatísticas foram realizadas utilizando-se o programa SAS (Statistical Analysis System, version 6). Para determinação das exigências de treonina digestível, foram utilizados três modelos de regressão: o modelo quadrático descrito por Robbins et al. (1979), o modelo exponencial descrito por Noll \& Waibel (1989) e o modelo de retas segmentadas ou Linear Response Plateau (LRP) descrito por Braga (1983), com 90\% do quadrado máximo, conforme o melhor ajustamento obtido para cada variável estudada.

\section{Resultados e Discussão}

Não houve efeito significativo $(\mathrm{P}>0,05)$ dos níveis de treonina das dietas sobre os parâmetros avaliados, exceto a conversão alimentar (Tabelas 3 e 4; Figura 1). Não se observou efeito do nível de treonina da ração $(\mathrm{P}>0,05)$ sobre o ganho de peso, o consumo de ração e a viabilidade criatória (Tabela 3). O nível de 0,6441\% de treonina digestível, correspondente à relação treonina:lisina digestível de $60 \%$, foi suficiente para atender à exigência (para máximo desempenho) de machos alimentados com dietas contendo 17,76\% de proteína bruta. Esses resultados diferem dos encontrados por Soares et al. (1999), que indicam valor de treonina digestível inferior $(0,57 \%)$ ao encontrado neste experimento para machos Hubbard na fase de 22 a 42 dias de idade. Leclercq (1998) propõe valores de 0,61\% de treonina digestível para ganho de peso utilizando o modelo descontínuo e Webel et al. (1996) indicam 0,61\% de treonina total para ganho de peso. Mack et al. (1999), utilizando o modelo descontínuo, recomendaram uma relação treonina:lisina de 63\% para as linhagens Ross e Isa na fase de 20 a 40 dias, portanto, muito próxima da menor relação utilizada neste experimento (60\%).

Não foi realizado ajuste adequado pelos modelos quadrático ou exponencial aos dados de desempenho das aves, uma vez que esses modelos não foram significativos (P>0,05) pela análise de variância da regressão. A resposta 
Tabela 2 - Composição percentual das rações experimentais

\begin{tabular}{|c|c|c|c|c|c|c|}
\hline \multirow[t]{2}{*}{ Ingrediente } & \multicolumn{6}{|c|}{ Nível de treonina digestível (\%) } \\
\hline & 0,5904 & 0,6441 & 0,6977 & 0,7514 & 0,8051 & 0,8588 \\
\hline Milho & 66,62 & 66,62 & 66,62 & 66,62 & 66,62 & 66,62 \\
\hline Óleo de soja & 3,03 & 3,03 & 3,03 & 3,03 & 3,03 & 3,03 \\
\hline Fosfato bicálcico & 1,63 & 1,63 & 1,63 & 1,63 & 1,63 & 1,63 \\
\hline Calcário calcítico & 0,96 & 0,96 & 0,96 & 0,96 & 0,96 & 0,96 \\
\hline DL- metionina & 0,20 & 0,20 & 0,20 & 0,20 & 0,20 & 0,20 \\
\hline L-treonina & 0,00 & 0,0537 & 0,1074 & 0,1611 & 0,2148 & 0,2685 \\
\hline L- arginina & 0,06 & 0,06 & 0,06 & 0,06 & 0,06 & 0,06 \\
\hline L-valina & 0,09 & 0,09 & 0,09 & 0,09 & 0,09 & 0,09 \\
\hline L-isoleucina & 0,05 & 0,05 & 0,05 & 0,05 & 0,05 & 0,05 \\
\hline Suplemento mineral + vitamínico* & 0,50 & 0,50 & 0,50 & 0,50 & 0,50 & 0,50 \\
\hline Proteína bruta $(\%)$ & 17,76 & 17,76 & 17,76 & 17,76 & 17,76 & 17,76 \\
\hline Energia metabolizável (kcal/kg) & 3.175 & 3.175 & 3.175 & 3.175 & 3.175 & 3.175 \\
\hline Cálcio (\%) & 0,87 & 0,87 & 0,87 & 0,87 & 0,87 & 0,87 \\
\hline Sódio (\%) & 0,21 & 0,21 & 0,21 & 0,21 & 0,21 & 0,21 \\
\hline Fósforo total (\%) & 0,63 & 0,63 & 0,63 & 0,63 & 0,63 & 0,63 \\
\hline Fósforo disponível (\%) & 0,41 & 0,41 & 0,41 & 0,41 & 0,41 & 0,41 \\
\hline Lisina digestível (\%) & 1,0735 & 1,0735 & 1,0735 & 1,0735 & 1,0735 & 1,0735 \\
\hline Metionina digestível (\%) & 0,466 & 0,466 & 0,466 & 0,466 & 0,466 & 0,466 \\
\hline Metionina + cistina digestível (\%) & 0,77 & 0,77 & 0,77 & 0,77 & 0,77 & 0,77 \\
\hline Triptofano digestível (\%) & 0,18 & 0,18 & 0,18 & 0,18 & 0,18 & 0,18 \\
\hline Treonina digestível $(\%)^{* *}$ & 0,5904 & 0,6441 & 0,6977 & 0,7514 & 0,8051 & 0,8588 \\
\hline Arginina digestível (\%) & 1,13 & 1,13 & 1,13 & 1,13 & 1,13 & 1,13 \\
\hline
\end{tabular}

Tabela 3 - Consumo de ração, ganho de peso, conversão alimentar, viabilidade criatória e índice de eficiência produtiva de frangos de corte alimentados com rações contendo diferentes níveis de treonina digestível de 22 a 42 e 1 a 42 dias de idade

\begin{tabular}{|c|c|c|c|c|c|}
\hline \multirow{2}{*}{$\begin{array}{l}\text { Nível de treonina } \\
\text { digestível (\%) }\end{array}$} & \multicolumn{5}{|c|}{ Parâmetros de desempenho } \\
\hline & $\begin{array}{l}\text { Consumo de } \\
\text { ração (kg) }\end{array}$ & $\begin{array}{l}\text { Ganho de } \\
\text { peso }(\mathrm{kg})\end{array}$ & $\begin{array}{c}\text { Conversão } \\
\text { alimentar }(\mathrm{kg} / \mathrm{kg})\end{array}$ & $\begin{array}{c}\text { Viabilidade } \\
\text { criatória (\%) }\end{array}$ & $\begin{array}{l}\text { Índice de eficiência } \\
\text { de produção } \\
\text { (1 a } 42 \text { dias de idade) }\end{array}$ \\
\hline 0,5904 & 3,202 & 1,756 & $1,823 \mathrm{~B}$ & 97,92 & $350,52 B$ \\
\hline 0,6441 & 3,179 & 1,760 & $1,807 \mathrm{AB}$ & 98,96 & $356,90 \mathrm{AB}$ \\
\hline 0,6977 & 3,239 & 1,779 & $1,821 \mathrm{AB}$ & 98,96 & $357,41 \mathrm{AB}$ \\
\hline 0,7514 & 3,144 & 1,780 & $1,766 \mathrm{~A}$ & 98,41 & $364,00 \mathrm{~A}$ \\
\hline 0,8051 & 3,231 & 1,810 & $1,784 \mathrm{AB}$ & 98,44 & $364,00 \mathrm{~A}$ \\
\hline 0,8588 & 3,217 & 1,817 & $1,769 \mathrm{AB}$ & 97,89 & $365,03 \mathrm{~A}$ \\
\hline Valores de P & $0,7510 \mathrm{NS}$ & $0,4181 \mathrm{NS}$ & $0,0493^{*}$ & $0,9582 \mathrm{NS}$ & $0,0358 *$ \\
\hline CV (\%) & 4,30 & 3,97 & 2,71 & 2,98 & 3,49 \\
\hline
\end{tabular}

NS = não-significativo; $* \mathrm{P}<0,05$.

Médias na coluna seguidas de letras diferentes diferem entre si $(\mathrm{P}<0,05)$ pelo teste Duncan.

de conversão alimentar foi ajustada adequadamente pelo modelo LRP (Tabela 5), onde o nível ótimo de treonina na ração, estimado pelo intercepto da reta ascendente com o platô, foi de $0,7642 \%$, discordando dos achados de Dozier III et al. (2000b), que estimaram a exigência de treonina em torno de $0,67 \%$ para frangos de corte machos criados em altas temperaturas ambientais na fase de 42 a 56 dias de idade para se alcançar a melhor conversão alimentar.

Com base no modelo LRP, o nível estimado de $0,7642 \%$ de treonina digestível na dieta pode ser interpretado como 
aquele a partir do qual não ocorre melhora na conversão alimentar das aves, valor superior às recomendações do NRC (1994), de 0,74\%, em rações com 3.200 kcal EM/kg de ração; de Rostagno et al. (2000), que recomendaram o nível de $0,69 \%$ de treonina digestível para bom desempenho de frangos de corte na fase de 22 a 42 dias de idade; e também de Samandi \& Liebert (2006, 2007), que encontraram o nível de $0,73 \%$ de treonina digestível para promover o máximo desempenho de frangos de corte de 30 a 45 dias de idade.

Com relação ao índice de eficiência produtiva, o nível 0,5904\% promoveu o pior resultado, embora não tenha diferido estatisticamente dos níveis 0,6441 e 0,6977\%, que, por sua vez, não diferiram dos demais níveis testados. De acordo com Moro et al. (2005), este índice vem aumentando significativamente nos últimos anos, devido às melhorias nos mais diferentes segmentos da produção como nutrição, genética, sanidade, manejo, ambiência, entre outros.

Os valores de exigências de treonina total observados por Penz Junior et al. (1991) para ganho de peso e eficiência alimentar de machos e fêmeas foram de 0,66 e 0,68\%, respectivamente, em pesquisa com frangos de corte de 22 a 42 dias de idade. Rangel-Lugo et al. (1994), no entanto, encontraram níveis de 0,63 e 0,69\% de treonina para ganho de peso e conversão alimentar de frangos de corte na fase de crescimento. Kidd \& Kerr (1996) relataram que dietas contendo níveis limitantes de treonina podem causar prejuízos pela piora da conversão alimentar, não afetando, porém, o peso corporal e o rendimento de carcaça. Em outro experimento, esses autores relataram que os melhores níveis para rendimento de carne de peito e de ganho de peso são, respectivamente, 0,75 e $0,65 \%$, e o nível de $0,74 \%$ estabelecido pelo NRC (1994) é inadequado para o ótimo desenvolvimento do frango de corte na fase de crescimento.

Neste estudo o nível de lisina digestível das rações experimentais foi de $1,0735 \%$ e os níveis de treonina digestível encontrados para melhor conversão alimentar $0,7642 \%$ e $0,7514 \%$ sendo as proporções de treonina digestível em relação à lisina digestível, dentro do conceito de proteína ideal, de aproximadamente 71,19\% segundo o modelo LRP. Esses valores estão de acordo com os observados por Kidd \& Kerr (1996) e Dionizio et al. (2003), mas foram superiores aos $67 \%$ sugeridos por Baker \& Han (1994), aos 63\% encontrados por Soares et al. (1999), aos $57 \%$ e $65 \%$ sugeridos por Rostagno et al. (2000) e Rostagno et al. (2005), respectivamente, e aos $68,5 \%$ obtidos por Emmert \& Baker (1997) para a fase de 21 aos 56 dias de idade.

De acordo com Doeschate (1999), a relação é de 65\% para a fase de 1 a 21 dias de idade e de $68 \%$ para a fase de 22 a 49 dias de idade. Devido à grande variabilidade de resultados descritos, mais trabalhos são necessários para confirmar esses achados. Atencio et al. (2004), trabalhando com frangos de corte machos dos 24 aos 38 dias de idade, também não encontraram evidências da influência da relação treonina:lisina sobre as características de desempenho, e

Tabela 4 - Equações ajustadas para conversão alimentar (CA), em função dos níveis de treonina digestível, coeficientes de determinação $\left(\mathrm{R}^{2}\right)$, e níveis de treonina estimados (NTreo) com o uso dos diferentes modelos

\begin{tabular}{lcc}
\hline Modelo & Variável / equação & NTreo (\%) \\
\hline Linear & $\mathrm{CA}=1,9455-0,2074 \times$ Ntreo & - \\
LRP & $\mathrm{CA}=1,777+0,2921 \times(0,764-$ NTreo $)$ & 0,68 \\
\hline
\end{tabular}

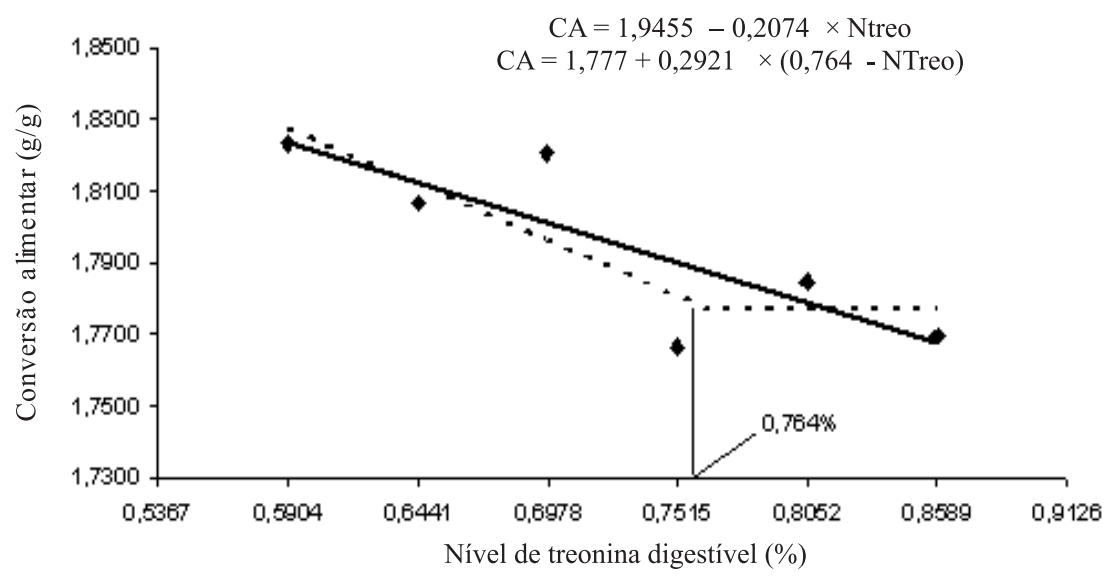

Figura 1 - Nível de treonina digestível na ração adequado para maximizar a conversão alimentar, estimado por meio do primeiro intercepto da equação linear com o platô do LRP para frangos de corte de 22 a 42 dias de idade. 
indicaram a relação de $60 \%$ como ideal para atender às exigências das aves. Berres et al. (2007) recomendaram a relação treonina:lisina de 68,5\% para frangos de corte de 15 a 37 dias de idade.

Webel et al.(1996), utilizando rações com 20\% de proteína bruta, encontraram o valor de $0,70 \%$ de treonina total para máximo desempenho de frangos de corte machos no período de 22 a 42 dias de idade. Segundo esses autores, o nível de treonina total para alcançar a máxima eficiência alimentar na fase de 22 a 42 dias de idade é de $0,72 \%$ e a relação ótima treonina:lisina é $70 \%$ para a fase de 21 a 56 dias de idade.

Segundo Corzo et al. (2006, 2007), os níveis ótimos de treonina total e de treonina digestível em relação à lisina digestível encontrados foram, respectivamente, 0,74 e $66 \%$ para ganho de peso e 0,72 e $64 \%$ para conversão alimentar das aves criadas em cama nova e 0,77 e 69\% para ganho de peso e 0,73 e $65 \%$ para conversão alimentar de frangos de corte criados em cama reutilizada na fase de 21 a 42 dias de idade.

Os níveis de treonina digestível da ração não influenciaram significativamente $(\mathrm{P}>0,05)$ os rendimentos de carcaça e das partes (Tabela 5). Não foi realizado ajuste adequado pelos modelos quadrático, exponencial e LRP aos dados de rendimento de carcaça das aves, uma vez que estes não foram significativos $(\mathrm{P}>0,05)$ pela análise de variância da regressão. Embora não se tenha verificado efeito significativo dos níveis de treonina sobre as características de carcaça, numericamente, o nível de 0,6441\% de treonina digestível indicou melhor rendimento de peito, coxa + sobrecoxa e asas em relação aos demais cortes. Esse valor difere numericamente da resposta encontrada por Soares et al. (1999) para machos.

O mesmo foi observado por Kidd \& Kerr (1996), que, avaliando o efeito de diferentes níveis de treonina em rações para frangos de corte sobre o rendimento de carcaça, relataram que o melhor desenvolvimento para carne de peito ocorreu com as aves que receberam dietas com $0,75 \%$ de treonina na fase final de criação (30 a 42 dias de idade) em relação àquelas que receberam dietas com $0,55 \%$ deficientes em treonina. Dozier III et al. (2000a) estimaram requerimento de $0,62 \%$ de treonina total para máximo rendimento de carcaça de frangos de corte de 42 a 56 dias de idade.

Em experimento com frangos de corte de 30 a 42 dias de idade, arraçoados com dieta contendo $3.200 \mathrm{kcal}$ EM/kg e 1,10\% de lisina, Kidd \& Kerr (1997) estimaram exigência de treonina total de $0,78 \%$ da dieta para rendimento de peito. Atencio et al. (2004) observaram efeito linear dos níveis de treonina digestível sobre o rendimento de perna na fase de 24 a 38 dias de idade. Reginatto et al. (2000) concluíram que a suplementação de treonina não influencia a composição das carcaças. Da mesma forma, Kidd et al. (2002a) não encontraram diferenças entre a concentração de treonina dietética sobre os parâmetros de carcaça mensurados.

Tabela 5 - Rendimento de carcaça e dos cortes de frangos de corte alimentados com rações contendo diferentes níveis de treonina digestível de 22 a 42 dias de idade

\begin{tabular}{|c|c|c|c|c|c|}
\hline \multirow[t]{2}{*}{ Níveis de treonina digestível (\%) } & \multicolumn{5}{|c|}{ Parâmetro de rendimento ${ }^{1}$} \\
\hline & Carcaça (\%) & Peito (\%) & Coxa + sobrecoxa $(\%)$ & Dorso $(\%)$ & Asas (\%) \\
\hline 0,5904 & 71,623 & 34,723 & 31,126 & 23,512 & 10,446 \\
\hline 0,6441 & 71,224 & 35,488 & 31,242 & 22,976 & 10,587 \\
\hline 0,6977 & 71,411 & 34,976 & 30,869 & 23,221 & 10,456 \\
\hline 0,7514 & 71,270 & 35,234 & 30,965 & 23,214 & 10,423 \\
\hline 0,8051 & 71,528 & 34,450 & 31,232 & 23,236 & 10,514 \\
\hline 0,8588 & 71,256 & 35,077 & 31,090 & 23,173 & 10,353 \\
\hline Valores de $\mathrm{P}$ & $0,9786 \mathrm{NS}$ & $0,4680 \mathrm{NS}$ & $0,9553 \mathrm{NS}$ & $0,8406 \mathrm{NS}$ & 0,8149 NS \\
\hline CV (\%) & 1,66 & 3,08 & 2,91 & 3,27 & 3,25 \\
\hline
\end{tabular}

NS = não-significativo; CV = coeficiente de variação.

${ }^{1}$ Carcaça eviscerada sem pés, sem cabeça e sem pescoço.

De acordo com relatos de Leclercq (1998), que avaliou dietas com diversos níveis de treonina para frangos de corte machos dos 20 aos 40 dias de idade, apenas um nível muito baixo (0,48\% de treonina digestível) foi capaz de influenciar negativamente características como ganho diário, conversão alimentar e deposição de carne de peito.

\section{Conclusões}

Com base nos dados o modelo Linear Response Plateau, o nível de treonina digestível para melhor conversão alimentar de frangos de corte é de $0,7642 \%$, que corresponde à relação treonina:lisina digestíveis de 71,19\%. 


\section{Agradecimentos}

À FAPESP, pelo auxílio à pesquisa e pela bolsa de estudos concedida.

\section{Referências}

ATENCIO, A.; ALBINO, L.F.T.; ROSTAGNO, H.S. et al. Exigências de treonina para frangos de corte machos nas fases de 1 a 20 , 24 a 38 e 44 a 56 dias de idade. Revista Brasileira de Zootecnia, v.33, n.4, p.880-893, 2004.

BAKER, D.H.; HAN, Y. Digestible lysine requirement of male and female broiler chicks during the period three to six weeks post hatching. Poultry Science, v.73, p.1739-1745, 1994.

BERRES, J.; VIEIRA, S.L.; CONEGLIAN, J.L.B. et al. Respostas de frangos de corte a aumentos graduais na relação entre treonina e lisina. Ciência Rural, v.37, n.2, p.510-517, 2007.

BRAGA, J.M. Avaliação da fertilidade do solo (ensaios de campo). Viçosa, MG: Universidade Federal de Viçosa, 1983. 101p.

CORZO, A.; KIDD, M.T.; PHARR, G.T. et al. Immune and growth responses to dietary L-threonine of broilers raised in different litter conditions. Poultry Science, v.85 (Suppl. 1), p.32. (Abstr.), 2006.

CORZO, A.; KIDD, M.T.; DOZIER III, W.A. et al. Dietary threonine needs for growth and immunity of broilers raised under different litter conditions. The Journal of Applied Poultry Research, v.16, n.4, p.574-582, 2007.

DIONIZIO, M.A.; ROSTAGNO, H.S.; ALBINO, L.F.T. et al. Dietas vegetais com diferentes níveis de proteína e de relação treonina/ lisina para frangos de corte. Revista Brasileira de Ciência Avícola, v.5, p.69, 2003.

DOESCHATE, R.A.H.M. Nutrição de aminoácidos para frangos de corte:ciência e realidade comercial. In: SIMPÓSIO INTERNACIONAL ACAV EMBRAPA SOBRE NUTRIÇÃO DE AVES, 1., 1999, Concórdia. Anais... Concórdia, 1999. p.102-110.

DOZIER III, W.A.; MORAN, JUNIOR, E.T.; KIDD, M.T. Threonine requirement for broiler males from 42 to 56 days of age. The Journal of Applied Poultry Research, v.9, p.214-222, 2000a.

DOZIER III, W.A.; MORAN JUNIOR, E.T.; KIDD, M.T. Threonine requirement of broilermales from 42 to 56 days in a summer environment. The Journal of Applied Poultry Research, v.9, p.496-500, 2000b.

DOZIER III, W.A.; MORAN JUNIOR, E.T.; KIDD, M.T. Male and female responses to low and adequate dietary threonine on nitrogen and energy balance. Poultry Science, v.80, p.926-930, 2001.

EMMERT, J.L.; BAKER, D.H. Use of the ideal protein concept for precision formulation of amino acid levels in broiler diets. The Journal of Applied Poultry Research, v.6, n.4, p.462-470, 1997.

FERNANDEZ, S.R.; AOYAGI, S.; HAN, Y. et al. Limiting order of amino acid in corn and soyben meal cereal for growth of the chick. Poultry Science, v.73, p.1887-1896, 1994.

HENRY, Y.; SÉVE, B. Feed intake and dietary amino acid balance in growing pigs with especial reference to lysine, tryptophan and threonine. Pig News and Information, v.14, n.1, p.35-43, 1993.

KIDD, M.T.; KERR, B.J. Threonine responses in commercial broilers at 30 to 42 days, The Journal of Applied Poultry Research, v.6, p.362-367, 1997.

KIDD, M.T. Nutritional considerations concerning threonine in broilers. World's Poultry Science Journal, v.56, p.139-151, 2000.

KIDD, M.T.; KERR, B.J. Threonine and broiler nutrition. In: MEETING ARKANSAS NUTRITION CONFERENCE, 1996, Fayetteville. Proceedings... Fayetteville: The Poultry Federation, 1996. p.203-228.
KIDD, M.T.; CORZO, A.; DOZIER III, W.A. et al. Practical dietary L-Threonine inclusion and resultant impact on broiler growth, yield, and nitrogen excretion. Poultry Science, v.86, p.1574, (Abstr.), 2007.

KIDD, M.T.; ZUMWALT, C.D.; CHAMBLEE, D.W. et al. Broiler growth and carcass responses to diets containing L-threonine versus diets containing threonine from intact protein sources. The Journal of Applied Poultry Research, v.11, n. 1, p.83-89, 2002a.

KIDD, M.T.; DOZIER III, W.A.; BARBER, S.J. et al. Threonine needs of Cobb male broilers from days 42 to 56. Poultry Science, v.81 (Suppl. 1), p.115, 2002b.

KIDD, M.T.; KERR, B.J.; ANTHONY, N.B. Dietary interactions between lysine and threonine in broilers. Poultry Science, v.76, n.4, p.608-614, 1997.

LECLERCQ, B. Specific effects of lysine on broiler production: comparison with threonine and valine. Poultry Science, v.77, p.118-123, 1998.

MACK, S.; BERCOVICI, D.; DEGROOTE, G. et al. Ideal amino acid profile and dietary lysine specifications for broiler chickens of 20 to 40 days of age. British Poultry Science, v.40, p.257-265, 1999.

MORO, D.N.; ZANELLA, I.; FIGUEIREDO, E.A.P. et al Desempenho produtivo de quatro linhagens de frangos de corte. Ciência Rural, v.35, n.2, p.446-449, 2005.

NOLL S.L.; WAIBEL, P.E. Lysine requirement of the growing turkey in various temperature environments. Poultry Science, v.68, n.6, p.781-794, 1989.

NATIONAL RESEARCH COUNCIL - NRC. Nutrients requirements of poultry. 9.ed. Washington, D.C.: National Academy Press, 1994. 155p.

PARSONS, C.M.; HASHIMOTO, K.; WEDEKIND, K.J. et al. Effect of overprocessing on availability of amino acids and energy in soybean meal. Poultry Science, v.71, p.133-140, 1992.

PENZ JUNIOR, A.M.; COLNAGO, G.L.; JENSEN, L.S. Threonine requirement of broiler chickens from 3 to 6 weeks of age. Poultry Science, p.70-93, 1991 (Abstract).

RANGEL-LUGO, M.; SU, C.L.; AUSTIC, R.E. Threonine requirement and threonine imbalance in broiler chicks. Poultry Science, v.73, p.670-681, 1994.

REGINATTO, M.F.; RIBEIRO, A.M.L.; PENZ JUNIOR, A.M. et al. Suplementação de treonina em dietas de frangos de corte, variando a energia e as relações energia:proteína. Revista Brasileira de Ciência Avícola, v.2, n.3, p.239-247, 2000.

ROBBINS, K.R.; NORTON, H.W.; BAKER, D.H. Estimation of nutrient requirements from growth data. The Journal of Nutrition, v.109, p.1710-1714, 1979.

ROBBINS, K.R. Threonine requirement of the chick as affected by protein level and source. Poultry Science, v.66, p.1531-1534, 1987.

ROSTAGnO, H.S.; ALBINO, L.F.T.; DONZELE, J.L. et al. Tabelas brasileiras para aves e suínos: composição de alimentos e exigências nutricionais. Viçosa, MG: Universidade Federal de Viçosa, 1996. 141p.

ROSTAGNO, H.S.; ALBINO, L.F.T; DONZELE, J.L. et al. Tabelas brasileiras para aves e suínos: composição de alimentos e exigências nutricionais. Viçosa, MG: Universidade Federal de Viçosa, 2000. 141p.

ROSTAGNO, H.S.; ALBINO, L.F.T.; DONZELE, J.L. et al. Tabelas brasileiras para aves e suínos: composição de alimentos e exigências nutricionais. 2.ed. Viçosa, MG: UFV, Departamento de Zootecnia, 2005. 186p.

SAMADI, F.; LIEBERT, F. Modeling of threonine requirement in fast-growing chickens, depending on age, sex, protein deposition, and dietary threonine efficiency. Poultry Science, v.85, n.11, p.1961-1968, 2006.

SAMADI, F.; LIEBERT, F. Threonine requirement of slow-growing male chickens depends on age and dietary efficiency of threonine utilization. Poultry Science, v.86, n.6, p.1140-1148, 2007. 
SILVA, D.J. Análise de alimentos: métodos químicos e biológicos. 2.ed. Viçosa, MG: Universidade Federal de Viçosa, 1990. 165p

SOARES, R.T.R.N.; ALBINO, L.F.T.; ROSTAGNO, H.S. et al. Exigência de treonina para frangos de corte no período de 22 a
42 dias de idade. Revista Brasileira de Zootecnia, v.28, n.1, p.127-131, 1999.

WEBEL, D.M.; FERNANDEZ, S.R.; PARSONS, C.M. et al. Digestible threonine requirement of broiler chickens during the period three to six and six to eight weeks posthatching. Poultry Science, v.75, p.1253-1257, 1996. 